\title{
Sentence Length and Complexity in Hemingway's Short story : A Clean, Well-Lighted Place : A Stylistic study
}

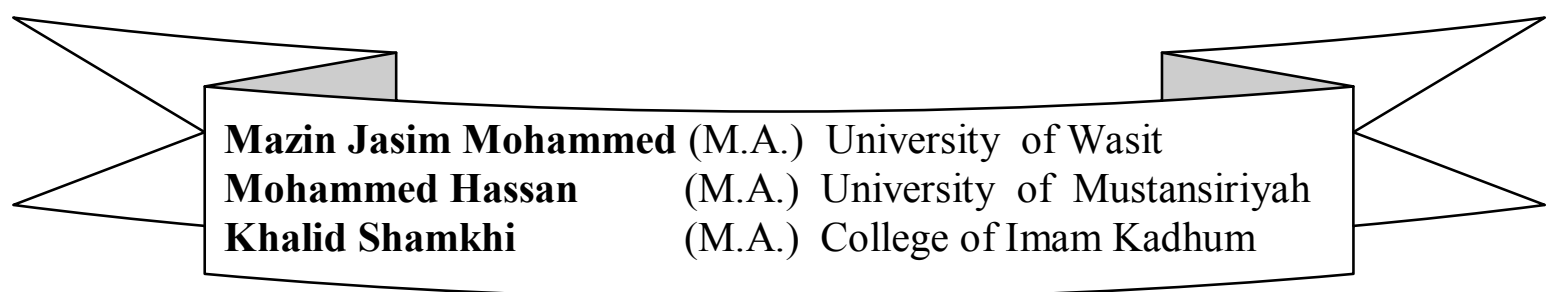

\section{Part I ( Theoretical Background )}

\subsection{The Concept of Style :}

The term style is somehow difficult to define . The difficulty arises from the fact that it is acquiring several interpretations. Such interpretations might refer to abstract notions such as " style of deviations "; or " style is choice " or a distinct personality (the style of Shakespeare ) ; or to periods ( the baroque style ) and the like

(Galperine , 1977:11).

Carter and Nashe (1990:36) argue that style can be recognized because it stands out in one way or another from a standard. This view simply means style can be seen as deviation. However, such a view cannot be taken for granted since norms are very difficult to standardize . Wales (1990) [quoted in Missikova ,2003] in her famous book A Dictionary of Stylistics listed the most common characteristics of style as follows :

1. Style refers to the manner of expression in writing and speaking .

2. Style can be seen as variation in language use, whether literary or nonliterary. The term register is commonly used for such variations in linguistic features found in non-literary situations ,

such as legal language, advertising, etc.

3. Style is seen as distinctive of register, genre or period.

4. Style is defined in terms of choice of items, and their distribution and patterning . 
As deviation from a norm, style is a concept that is used traditionally in literary stylistics, since literary language is more deviant than non-literary language use .

To sum up , Warner (1961:1) ; Garvin (1964:112) go on to state that in spite of the different interpretations of the term style, the simplest interpretation is that is a manner of expressing one's thoughts and feelings in words .

\subsection{The Scope of Stylistics :}

According to Enkvist (1973) [cited in Al-Omary ,1996:9], stylistics is considered a combined science of linguistics and literature, due to the fact that stylisticians always work on texts . Linguists were labeled stylisticians when approaching texts with textual methods of analysis ( Cassirer, $1975: 28$ ).

Leech \& Short (1981:38-39) define stylistics as the study of style; in other words, literary stylistics has to do with explaining the relation between style and literary function. Short (1996:27) emphasizes the role stylistic analysis plays in revealing literary or aesthetic functions by saying that :

stylistic analysis is a method of linking linguistic form, via reader inference, to interpretation in a detailed way and thereby providing as much evidence as possible for and against particular interpretations of text .

Stylistics has received much more interest during the last decades of the twentieth century since it touches upon various approaches concerned with particular aspects of text .Some of these approaches were made by linguists, psychologists, literary critics, anthropologists, and the like. Stylistic 
analysis contributes much to the development of literary criticism . Critics argue that a literary text can be comprehended better if it is studied in parallel with stylistic analysis

\subsection{About The Author}

The American writer Ernest Hemingway was born in Oak Park, Illinois, on July 21, 1899 and he can be identified as the most widely read serious fiction writer in America during the twentieth century (Shuman,2002: 659). Young (1985 :5) says about Hemingway that " no other novelist has had an equivalent influence on the prose of modern fiction". Shuman (ibid) writes that it is said, that the most important contribution to American literature is Hemingway's simple writing style, where he seems to leave out everything from the text except the most essential parts, by finding exactly the right words to use. Kartiganer (2004:54) remarks that "Hemingway perfected an art of exclusion" and says that Hemingway had a gift called the "built-in, shock-proof, shit detector", which he used to detect and erase all the words that did not work, leaving only the words that were of highest importance to his story.

Hemingway never went to college, instead he took a job with a newspaper called Kansas City Star, working as a journalist. Hemingway said that during his time as a reporter on the 'Star' he learned to write simple declarative sentences, use short paragraphs and first sentences, use vigorous English and to be cautious about adjective use -these were rules of writing he never forgot (Tyler,2001: 15-16).

At the end of Hemingway's life, he was very sick and diagnosed as manic-depressive, suffering from nightmares, paranoia, insomnia - a theme that also occurred in "A Clean, Well- Lighted Place" (Tyler 13). Beegel (1996:273)reports that Hemingway committed suicide by shooting himself in the head with a shotgun in Kethum on July 2, 1961.

\subsection{Hemingway's Style}


Hemingway writes in a clear and concise manner, alternating between long and descriptive sentences, to short, brief, and powerful ones that show the reader the facts. This effect produces a variance to Hemingway's composition, creating a much more hospitable environment for the reader to delve in.

"A Clean, Well-Lighted Place" is arguably not only one of Hemingway's best short stories but also a story that clearly demonstrates the techniques of Hemingway's signature writing style. Hemingway is known for his economic prose-his writing is minimalist and sparse, with few adverbs or adjectives. He includes only essential information, often omitting background information, transitions, and dialogue tags such as "he said" or "she said. He often uses pronouns without clear antecedents, such as using the word ' $i t$ ' without clarifying what 'it' refers to. Hemingway applies the "iceberg principle" to his stories: only the tip of the story is visible on the page, while the rest is left underwater-unsaid. Hemingway also rarely specifies which waiter is speaking in the story because he has deemed such clarification unnecessary. The essential element is that two waiters are discussing a drunk old man-the rest can be omitted according to Hemingway's economy of style. When the older waiter contemplates the idea of nothingness, Hemingway loads the sentences with vague pronouns, never clarifying what they refer to: "It was all a nothing. ... It was only that. ... Some lived in it ..." Although these lines are somewhat confusing, the confusion is the point. This nothingness can't be defined clearly, no matter how many words are used. Hemingway uses fewer words and lets the effect of his style.

\subsection{A Clean,Well-lighted Place: A Summary}

Two waiters are waiting to close up their café for the night. They only have one customer left - an old man, deaf, drunk, and seemingly peaceful. He's a regular at the café, and the waiters seem to know all about him. Apparently, the old man attempted to hang himself the previous week, but 
was stopped mid-suicide by his niece. The older waiter and younger waiter debate the possible cause.

Meanwhile, a soldier walks by with a young woman, presumably out beyond curfew. The waiters wonder idly if he will get picked up by the guard, but decide that it doesn't matter, as long as he gets what he wants from the girl.

The old man asks for another drink, and the younger waiter goes to serve him, disdainfully commenting that the old man should have killed himself . Watching the old man from afar, the two waiters return to their conversation about the his attempted suicide. The younger waiter thinks that old age is a terrible thing, but the older waiter disagrees - after all, this particular old man is still clean and proper, even when he's drunk. The old man signals for yet another drink, but this time, the younger waiter refuses, saying that they have to close up for the night. The old man carefully pays and leaves, drunk but dignified.

As the two waiters close up shop, they continue to argue mildly about the old man, and about people who "need" the café to stay open. The older waiter sympathizes with these people - he recognizes that sometimes someone might need to take refuge in a "clean, well-lighted place," rather than a dark, dim bar or bodega.

After the younger waiter hurries off home to his wife, the older waiter takes his time, continuing their argument in his mind. He realizes that life, when it comes down to it, is simply meaningless - and that we all need a brightly lit, pleasant place to sit to avoid thinking about the dark demons of death and nothingness. He stops at a bar, but finds that it's not to his liking, and continues home, ruefully commenting that his malaise is probably just insomnia . 


\section{Part II (The Analysis)}

\subsection{Methods of Analysis}

The model of analysis to be used in this paper is that of Leech \& Short ( 1981 ). They provide us a checklist which enable us to collect data on a fairly systematic basis. The categories of stylistic analysis of a text can be placed under four general headings : lexical categories, grammatical categories, figures of speech, and cohesion and context .It presents a comprehensive description under the grammatical category which best suits the purpose of the present paper. They put their model in the form of a checklist comprising a number of questions as far as the grammatical category is concerned. We can say some sentences relate to sentence complexity since there are other questions in the grammatical category . : Do sentences on the whole have a simple or complex structure? What is the average sentence length (in number of words)?What is the ratio of dependent to independent clauses? Does complexity vary strikingly from one sentence to another? Is complexity mainly due to(i)coordination, (ii)subordination,(iii)subordination, (iii)parataxis (juxtaposition of clauses or other equivalent structures)?In what parts of a sentence does complexity tend to occur?

The present paper tries to analyze Hemingway's short story in terms of these questions to explicate the effect of the language used on his style.

A sentence, in the present study, is "a complete structure found in written texts, bounded by sentence punctuation such as '.', '!', '?'. " (Biber, Conrad and Leech 460). The sentence length is presented against the norm for modern English. Short (1996:337) mentions that Ellegård (in 1978) produced a norm for modern English writing, where the average sentence length is said to have been 17.8 words per sentence. Because there was a chance that Hemingway might have used both long and short sentences, counting the average sentence length might have been misleading. 
Therefore the sentence length is also presented by counting the median. In this essay, median is the middle value from a list of observations ranging from the lowest values to the highest values.

To provide more accurate statistics as regards Hemingway's sentence length, all the sentences in the story were counted. The length of the sentences is also displayed in diagrams, showing the length of every sentence counted.

As for sentence complexity, the short story is analysed to determine the type of sentences used :simple or complex. The criteria followed in classifying the sentences as such are based on Quirk and Greenbaum's(1972) classification of sentences according to structure. Thus a sentence is simple if it consists of one subject and one verb and hence expresses one idea. If the sentence is not simple, it is then complex. By a complex sentence here it is meant either a compound, a complex , or a compound-complex. A compound sentence consists of two independent clauses joined by a conjunction such as 'and', 'but' or 'or' etc. A complex sentence is one with an independent clause and one or more dependent clauses subordinated to the independent clause by a subordinator. Finally, a compound-complex sentence is a compound clause subordinated to a main clause via a subordinator.

The occurrences of each type of sentences mentioned above are counted and the percentage of each is calculated against the total number of sentences used in the story.

One of the questions in the checklist offered by Leech and Short concerns sentence length and complexity. To make a general survey of this story, we perceive an interesting phenomenon, that is, the sentences about the author's narration are long but easily understood, while the dialogues of the characters are short but full of meaning, worth chewing over. For example,

It was very late and everyone had left the cafe except an old man 
who sat in the shadow the leaves of the tree made against the electric light. In the day time the street was dusty, but at night the dew settled the dust and the old man liked to sit late because he was deaf and now at night it was quiet and he felt the difference. The two waiters inside the cafe knew that the old man was a little drunk, and while he was a good client they knew that if he became too drunk he would leave without paying, so they kept watch on him.

There are three sentences in this extract with an average 36 words each. In the first sentence, the restrictive clause which modifies the character and functions as periodic structure arouses our curiosity---why does the old man sit late at night? The second sentence contains four clauses. They're linked by "and" to produce a long sentence. In this way the author describes a scene economically, and tells readers that the events are sequential and equally important.

They sat together at a table that was close against the wall near the door of the cafe and looked at the terrace where the tables were all empty except where the old man sat in the shadow of the leaves of the tree that moved slightly in the wind. A girl and a soldier went by in the street. The street light shone on the brass number on his collar. The girl wore no head covering and hurried beside him.

There are 50 words in the first sentence. The restrictive clauses give us no pause for breath. Our view simultaneously follows the narration from the two waiters to the door, and then to the terrace and the tables, at last our focal point rests on the old man, who is sitting with no companion except the shadow!

It is evident that the author describes the scene by "showing" rather than "telling". He presents series of objects one after another, through which he 
shares certain special thought and feeling with the reader. This technique is somewhat like shooting a film, which just presents the real scene to the audience.

On the other hand, sentences in conversation are succinct and uncomplicated but expressive. For example, "He's lonely. I'm not lonely. I have a wife waiting in bed for me." "He had a wife once too." This implies that the old man had everything that the young man has now. "What is an hour?" It means "what is the difference if you go back home an hour late".

Knight (149) says that short simple sentences are very common in Hemingway's writing, but also coordinated sentences: He specifically points out the ones using the conjunction and. Tyler (21-22) says that Hemingway's writing style is known for his "short declarative sentences, a preference for simple, often one-syllable words, and an emphasis on the concrete rather than the abstract." Beck, et.al.(2004:156) also state that short sentences, written clearly, simply and not containing too much information, are one of Hemingway's hallmarks.

\subsection{Results of Analysis}

The analysis for sentence length has come out with the following statistics which conform with what Hietanen (2009) has come out with since the same data were processed :

Number of words: 1434.

Number of sentences: 165 .

Average sentence length: 8.69 words.

Average sentence length norm for modern English (according to Ellegård): 17.8 words.

Median: 7.

Most common sentence length: 6 words $=22$ sentences $(13.33 \%$ of all the 
sentences).

Shortest sentence: 1 word used in 6 sentences (3.64\% of all the sentences).

Longest sentences: 50 words $=1$ sentence, 41 words $=1$ sentence, 40 words $=1$ sentence. 16

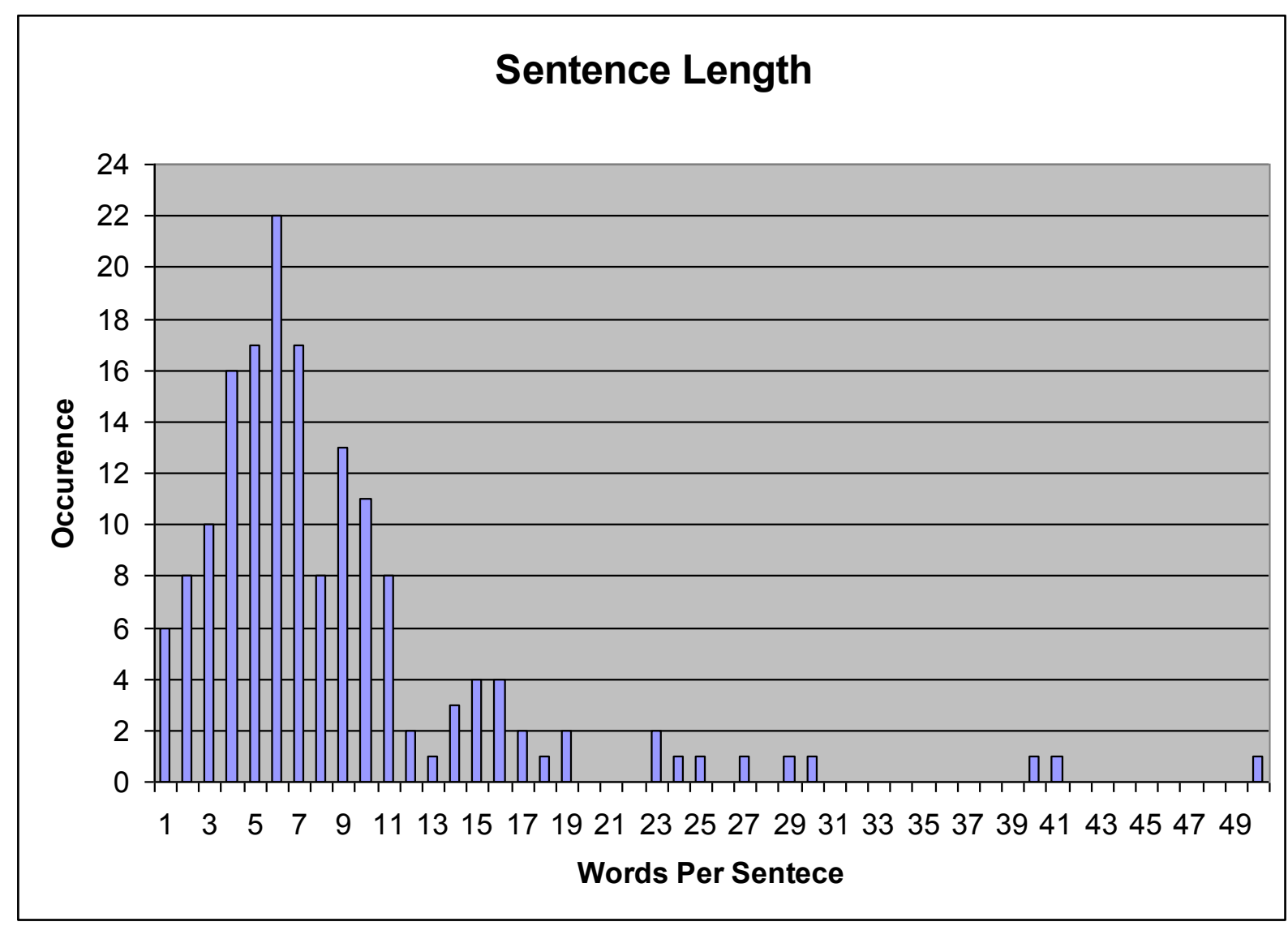

Diagram( 1) (Adapted from Hietanen ,2009)

In Diagram ( 1) the x-axis shows sentences with one to fifty words, and the y-axis shows how many times each sentence length occurs. In the Diagram( 1), one clearly sees how the lengths of the sentences are spread out. It is notable that only( 13) (7.89\%) sentences of the total (165) are above the average norm (17.8), and that (128) (77.58\%) sentences are between one and ten words long, since according to Ellegård the average is almost( 18 )words per sentence which is almost twice this amount. Since there are many short dialogues in" Place", this affects the average sentence length; and this can be seen by looking at the sentence length in the 
following dialogue :

"He's drunk every night."

"What did he want to kill himself for?"

" How should I know?"

"How did he do it?"

"He hung himself with a rope."

"Who cut him down?"

"His niece."

"Why did they do it?"

"Fear for his soul."

" How much money has he got?"

"He's got plenty. "

" He must be eighty years old."

As mentioned before, Hemingway is known for his use of short sentences, but he also likes to use long compound sentences, i.e. stacking clause and clause and clause after one another. The following example, with the indented extracts, is a part of a dialogue sequence from 'Place' and it shows how Hemingway uses 50 words in one sentence:

"They sat together at a table that was close against the wall near the door of the café and looked at the terrace where the tables were all 17 empty except where the old man sat in the shadow of the leaves of the tree that moved slightly in the wind.

As Knight (1995:149) says, Hemingway's coordinated sentences often use the conjunction and, but this is not the case in 'Place'. As you can see in the sentence above, and is used only once, and this can be said about the entire story; that the use of and does not occur often.

With regard to complexity of sentence structure the analysis yields the following results:

Total number of sentences: 165 


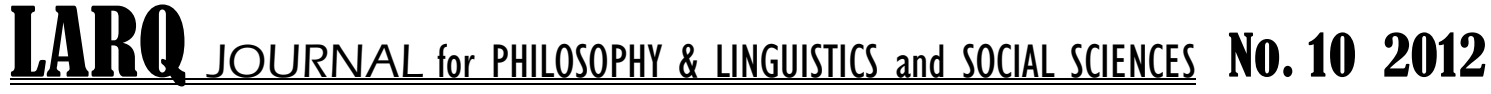

Simple sentence : 113

Complex sentence:52= 16 compound, 23 complex , 13 compound complex

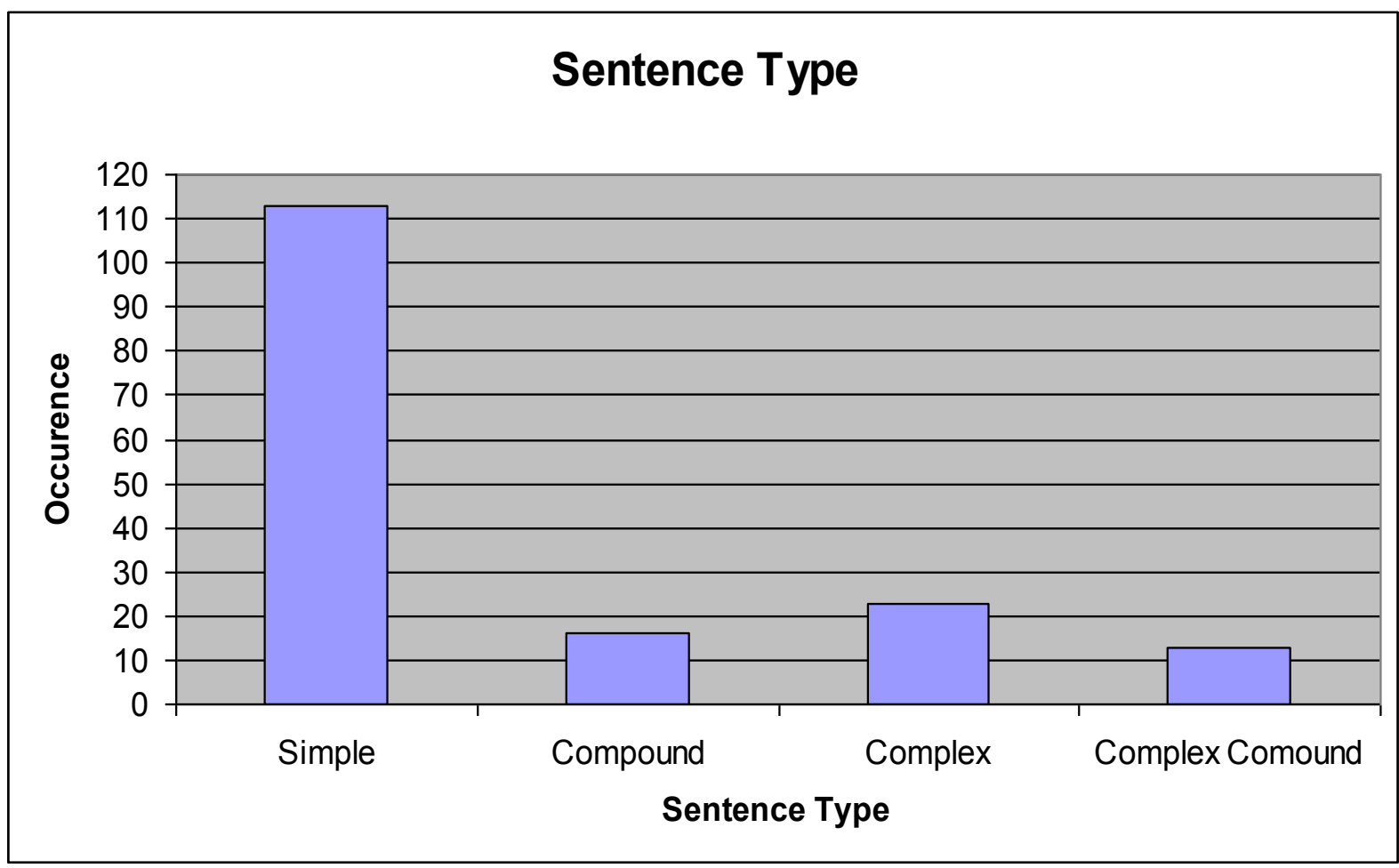

Diagram 2

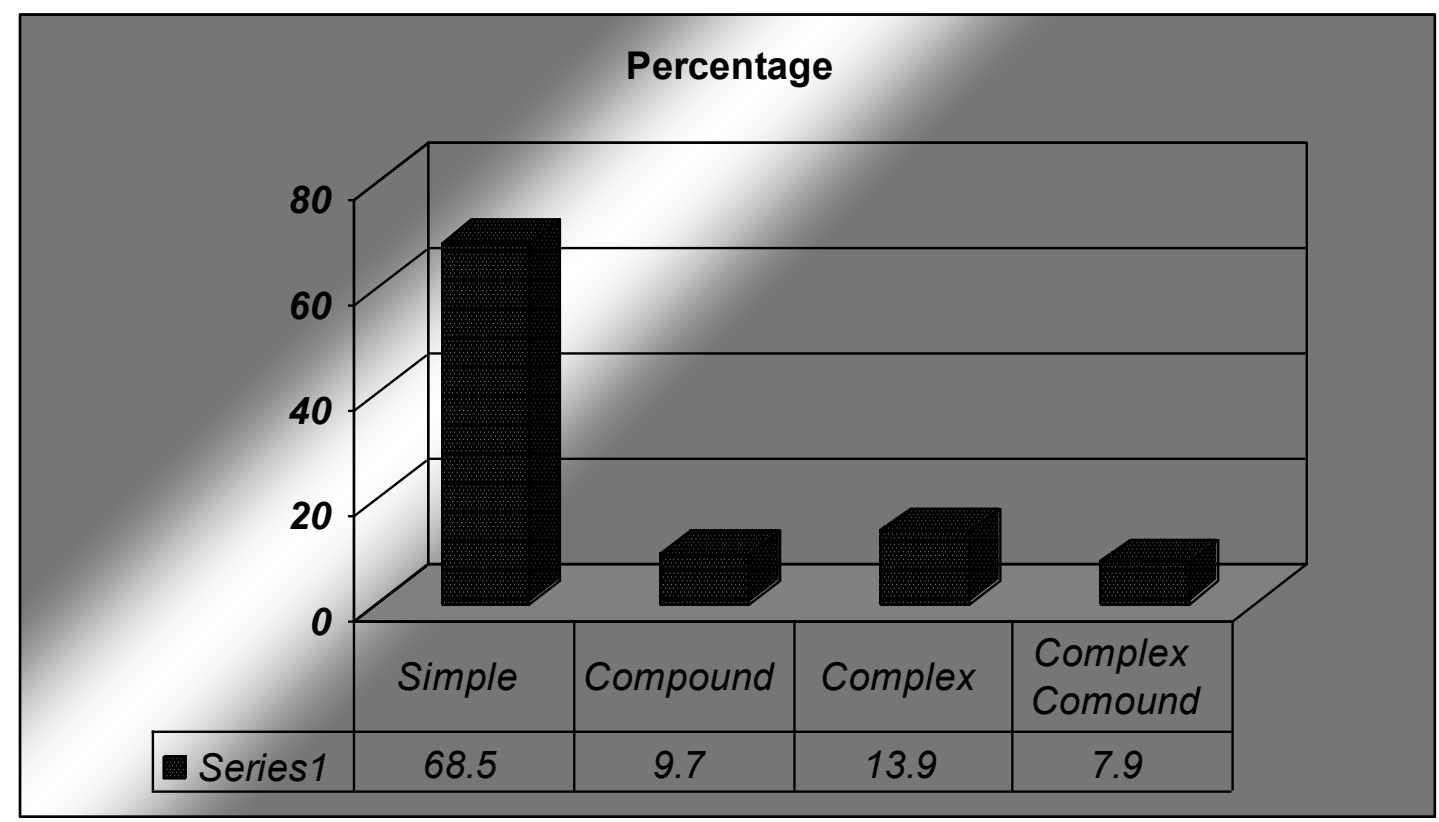

Diagram (3) 
As these numbers indicate the vast majority of sentences Hemingway uses in 'A Clean Well-lighted Place' are simple sentences .Out of 165 sentences used in the story( 113) are simple constituting ( 68.5\% )of the total number whereas complex sentences are (52) constituting (31.5) This finding proves the simplicity of style the author is famous for. The diagram illustrates the statistics and percentages of simple vs. complex sentences used in the short story.

\section{Types of Complexity :}

As has been mentioned earlier in Part II, the analysis of complex sentences relies heavily on Leech \& Short(1981). They, in their model, put forward a question regarding the source (s) of complexity, i.e., whether the source is due to : subordination, coordination, or parataxis . A careful analysis of the complex sentences ( 52) in number has the shown the following statistics represented by diagram ( 4 ).

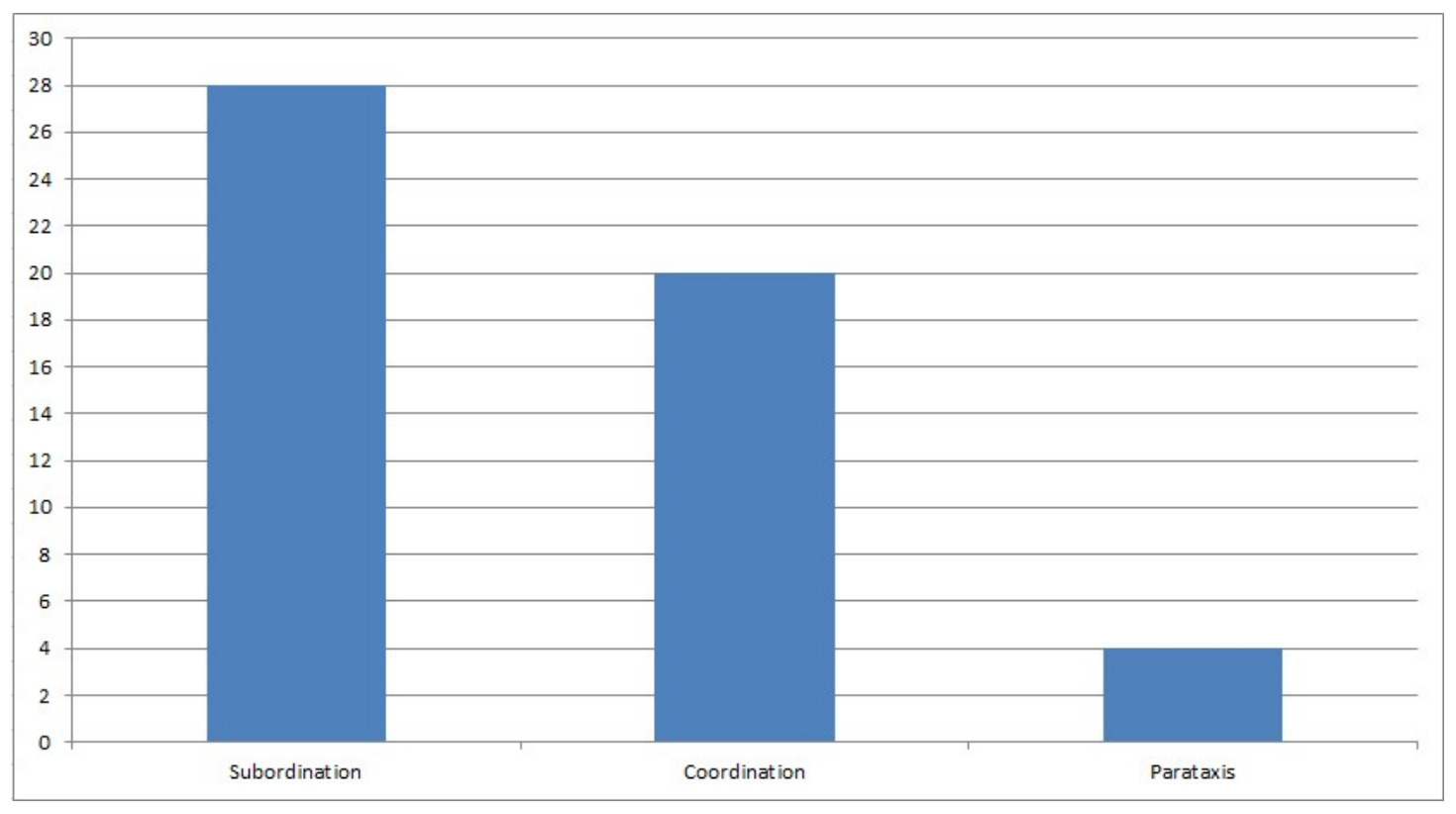

Diagram ( 4 ) Types of Complexity 
The analysis of complex sentences indicates that : out of (52) complex sentences of the text under analysis, it has been found that (28) were subordinated, constituting ( 53.9\%) ; the second source of complexity is represented by coordinated sentences (20) in number, constituting (38.4\%) ; while ( 4 ) complex sentences were due to parataxis, constituting ( 7.7\%).

As for the ratio of dependent to independent clauses, results have shown that the ratio is $(1: 8.47)$. This is of course due to the greater number of simple sentences than complex sentences in the story. Moreover, dependent clauses are only found in subordination occurring together with independent clauses while coordination and parataxis use independent clauses only.

\subsection{Conclusion}

In this paper, Hemingway's short story, A Clean, well-Lighted Place was stylistically studied according to leech and Short's(1981) model to give a clear idea about Hemingway's style which has been shown as distinctive and unique, being simple, direct and pithy. This can be seen in his preference of simplicity to complexity of expression through the use of much more simple sentences than complex ones .He uses simple structures, as is the case in most of his short stories ; this makes the story easy to understand .There are one-word sentences, in order to attract reader's attention and to express the feelings of his characters. Complex sentences formed by subordination, coordination and parataxis are used in certain cases especially in the speeches of the characters and thus help to create variation in the language used.

The simplicity of expression as well as absence of sentence interruption and the use of few emphatic elements all have the effect of making reading the story like listening to speech .Besides, the narrator's use of understatement implies greater depths of feeling than he puts into words. Like most of Hemingway's short stories, this story is no exception in having 
dialogues which allow readers to have understanding of his characters' feelings and relationships .

In the story, Hemingway emphasized the reactions of the characters to life which is meaningless (nada). Through it, he reveals his view of the world and his attitude to life. He views the world as a dark universe that is spiritually empty. The way to give meaning to life is to live with a certain kind of endurance and courage.

In the last, we can say the analysis of the stylistic features of the Place, as far as grammatical categories are concerned, certainly bring out some specific features of Hemingway's writing style . 
Bibliography

Beck,et.al . (2004 ). Communication Studies: The Essential Resource.

London: Routledge .

Beegel, F. Susan (1996 ). "Conclusion: The Critical Reputation of Ernest

Hemingway ". The Cambridge Companion to Ernest Hemingway.

Scott Donaldson, (ed.) Cambridge: Cambridge University Press.

Biber, D., Conrad, S. and Leech, G.(2008). Longman Student

Grammar of Spoken and Written English. Harlow: Pearson

Education Limited.

Carter, R. and Nash, W. (1990). Seeing Through Language: A Guide to

Styles of English Writing. Oxford : Blackwell Publishers.

Cassirer, P.(1975). " On the Place of Stylistics " in Haken Ringbom (ed.) (1975) pp. 27-41.

Enkvist, N.E . (1973) . Linguistic Stylistics . The Hague : Mouton .

Galperine, I.R. (1977) . Stylistics . Moscow : Higher School Press .

Hietanen, M. (2009) . A Stylistic Comparison of Two Short Stories by

Ernest Hemingway. Larnande : Hostterminen

Kartiganer, M. Donald (2004). "Getting Good at Doing Nothing \| :

Faulkner, Hemingway, and the Fiction of Gesture ". Faulkner and

His Contemporaries. Ann J. Abadie \& Joseph R Urgo. Jackson

(eds.) New York : University Press of Mississippi.

Knight, Christopher (1995). The Patient Particulars: American

Modernism and the Technique of Originality. London: Associated

University Press .

Leech, Geoffrey and Short, Michael. Style in fiction: A Linguistic introduction to English Fictional Prose. London: Longman, 1981[1992].

Missikova, G. (2003) . Linguistic Stylistics . Nitra: Univerzita Konstantina Press .

Al-Omary , D.F. (1996) . Some Linguistic Characteristics of Personal and Business Correspondence in English . Unpublished MA Thesis, University of Baghdad .

Short, M. (1996). Exploring the Language of Poems , Plays and Prose . London : Longman .

Shuman, R. B. ( Ed.) (2002) . Great American Writers: Twentieth Century. New York: Marshall Cavendish .

Tyler, L.(2001) . Student Companion to Ernest Hemingway. London: Greenwood Press .

Wales, K. ( 1991 ). A dictionary of Stylistics . London : Longman . 
Warner, A. (1961). A Short Guide to English Style . Oxford: OUP.

Young, P.(1985) ." Ernest Hemingway - American Writers 1": University of Minnesota Pamphlets on American Writers No.1. Minneapolis: University of Minnesota Press . 